\title{
Thirty-six pulse rectifier scheme based on zigzag auto-connected transformer
}

\author{
Chen XiaO-Qiang ${ }^{1}$, Hao Chun-Ling ${ }^{1}$, QiU HaO ${ }^{1}$, Li Min $^{2}$ \\ ${ }^{1}$ School of Automation and Electrical Engineering \\ Lanzhou Jiaotong University \\ Anning West Road No. 88, Anning District, Lanzhou, 730070, China \\ e-mail:qh_zju@sina.com \\ ${ }^{2}$ School of International Education \\ Lanzhou Jiaotong University \\ Anning West Road No. 88, Anning District, Lanzhou, 730070, China
}

(Received: 24.04.2015, revised: 28.09.2015)

\begin{abstract}
In this paper, a low kilo-volt-ampere rating zigzag connected autotransformer based 36-pulse rectifier system supplying vector controlled induction motor drives (VCIMD) is designed, modeled and simulated. Detailed design procedure and magnetic rating calculation of the proposed autotransformer and interphase reactor is studied. Moreover, the design process of the autotransformer is modified to make it suitable for retrofit applications. Simulation results confirm that the proposed 36-pulse rectifier system is able to suppress less than $35^{\text {th }}$ harmonics in the utility line current. The influence of load variation and load character is also studied to demonstrate the performance and effectiveness of the proposed 36-pulse rectifiers. A set of power quality indices at AC mains and DC link are presented to compare the performance of 6-, 24- and 36-pulse AC-DC converters.
\end{abstract}

Keywords: autotransformer, harmonic suppression, multipulse rectifier, power quality

\section{Introduction}

Squirrel cage induction motor drives have gradually gained importance in industrial applications because of their advantages such as reliability, free maintenance, and low cost. In addition, the technique of vector control $[1,2]$ is widely employed to control induction motor drives since it has superior speed regulation performance.

Commonly, the power supply of VCIMD comprises a 6-pulse diode bridge rectifier, an L-C high pass filter, and a three phase voltage source inverter (VSI), as shown in Figure 1. The drawback of the 6-pulse diode rectifier is its injection of harmonic currents into the AC mains, low efficiency, and poor power factor [3]. When current harmonics circulate into the finite source impedance, they bring about voltage distortions at the point of common coupling (PCC), consequently influencing neighbouring consumers. The increasing use of induction motor drives has urged the need to give clear limits for current and voltage harmonics in- 
jecting into the power grid. Hence, many standards regarding power quality have been issued, such as IEEE 519-1992 [4] and IEC 61000-3-2 [5].

For alleviating utility current and utility voltage distortion, one of the most simple and robust harmonic mitigation solutions is to implement multipulse AC-DC converter $[3,6]$. The autotransformer based multipulse AC-DC converters can further reduce magnetic ratings, as the windings are interconnected and only a small portion of the total kilo-volt-ampere $(\mathrm{kVA})$ of the load is transferred through magnetic coupling. B. Singh et al. [7-15] explored various connections, such as Scott, tapped-delta, fork, hexagon, delta-polygon, and star connected autotransformer based multipulse rectifiers for induction motor drives load. The pulse number ranges from 12-pulse to 30-pulse. Twelve- and 20-pulse AC-DC converters based on deltapolygon autotransformer for medium capacity switched mode power supply (SMPS) was presented by Kalpana et al. [16, 17]. The proposed transformer used both multi-phase and phaseshifting techniques for harmonic current and magnetic ratings reduction. Oliveira [18] investigated the relationship between the output voltages on the secondary winding and the voltage reference from the primary winding of delta or wye autotransformer connection. Based on the obtained general expression, optimum operation points for 12- and 18-pulse delta or wye autotransformer based rectifiers were given. A mathematical analysis on the basis of phasor diagrams of delta or wye-connected autotransformers was discussed by Fernandes et al. [19]. The obtained expression simplified the process to determine turn ratios and polarities for all windings of the autotransformer.

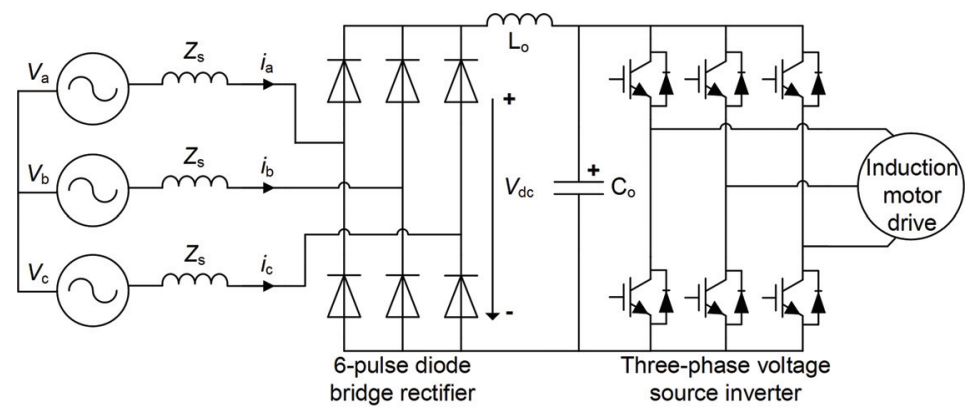

Fig. 1. Six-pulse diode bridge rectifier supplying VSI and VCIMD

With higher number of pulses, improvements in various power quality indices can be achieved, but at the expense of increased magnetics complexity and additional number of bridge converters. Literature [20] presented 24-pulse AC-DC converter based on zigzag autowound transformer. The design of the transformer is also modified to make it appropriate for retrofit applications. For more stringent power quality standards, rectifier systems of 30-pulse or higher must be used. A delta type autotransformer based 36-pulse rectifier was designed in reference [21], the proposed system could reduce the total harmonic distortion (THD) of the AC mains current down to $3.80 \%$ and the 36-stpped utility current was very close to sinusoidal wave. Abdollahi [22-25] proposed Scott, delta/polygon, polygon, and delta/hexagon connected autotransformer based 36-pulse AC-DC converters, which supplied induction motor 
drives to improve power quality at the PCC. Several rectifier systems based on autotransformer with double-tap or triple-tap changer were included in references [26-29]. The multitap changer utilized DC ripples reinjection technique, which could improve power quality criteria of the proposed converters without much alteration in the installations.

This paper analyzes a zigzag auto-wound transformer based 36-pulse rectifier scheme feeding a VCIMD at full length. Furthermore, the design of the proposed autotransformer is modified to make it appropriate for applications, where presently a 6-pulse rectifier is used. Theoretical kVA ratings of the autotransformer and interphase reactor are obtained. MATLAB model of the 36-pulse rectifier and the zigzag autotransformer is also given. Simulation results of four different topologies are presented and different power quality parameters such as THD of supply current, THD of supply voltage at PCC, distortion factor (DF), displacement factor (DPF), power factor (PF), and ripple factor (RF) are tabulated and compared.

The rest of the paper is organized as follows. In Section 2, 36-pulse rectifier scheme based on zigzag autotransformer is introduced. The MATLAB simulation models are shown in Section 3. In Section 4, simulation results are given and performance of four different topologies is discussed. The conclusion is made in Section 5 .

\section{The proposed 36-pulse rectifier}

Multipulse technique utilizes multiple 6-pulse bridge converters, where the harmonic components generated by one converter are canceled by harmonic currents produced by other converters through proper phase shift. For harmonic reduction in the utility current, the minimum phase shift required should be [6]: Phase shift $=60^{\circ} /$ Number of 6-pulse converters.

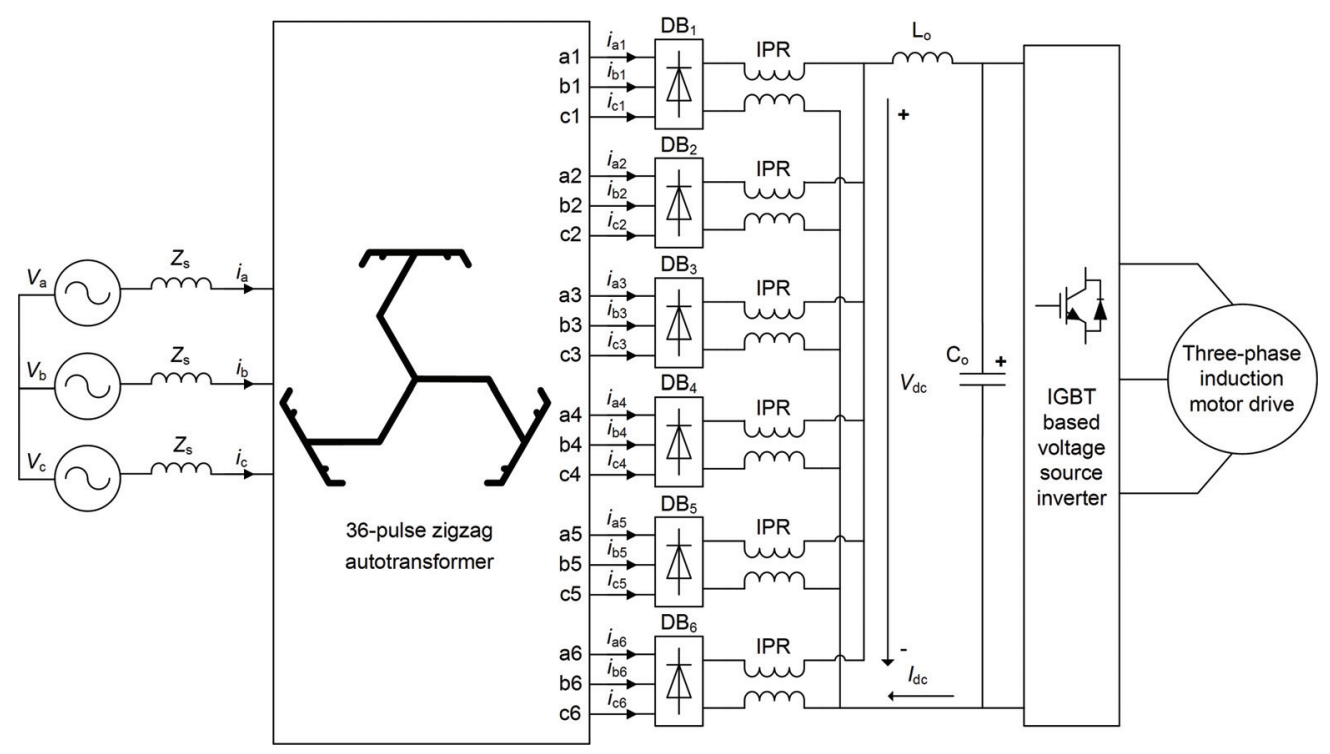

Fig. 2. Zigzag transformer based 36-pulse AC-DC converter 
In order to accomplish 36-pulse rectification, the required minimum phase shift among different groups of three-phase voltages is $10^{\circ}$. For the purpose of reducing the size of the proposed autotransformer, the phase shift angle is chosen to be $\pm 5^{\circ}, \pm 15^{\circ}$, and $\pm 25^{\circ}$. Figure 2 illustrates the circuit diagram of the devised 36-pulse AC-DC converter based on zigzag autotransformer. The system consists of three phase AC voltage source, phase-shifting autotransformer, six diode bridges, two interphase reactors, and induction motor drive load.

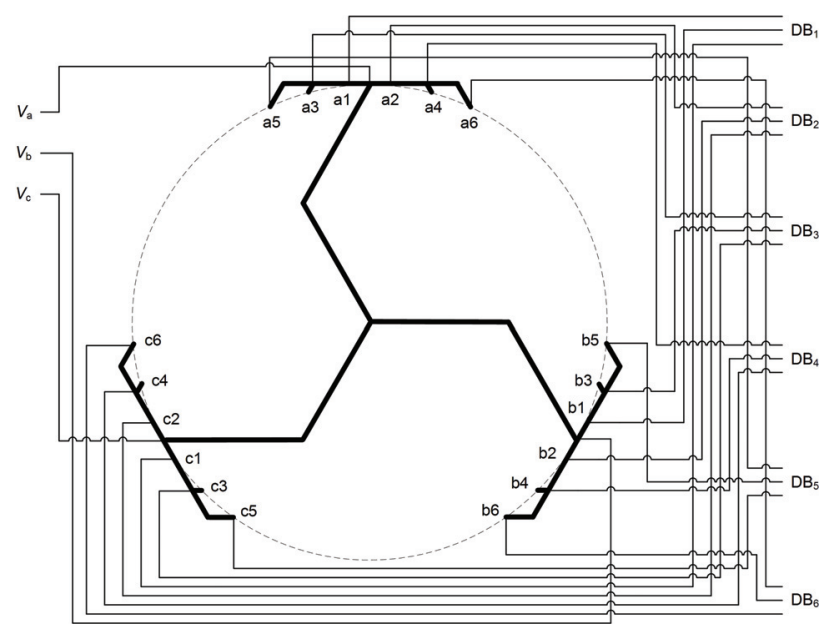

Fig. 3a. Winding configurations of zigzag autotransformer

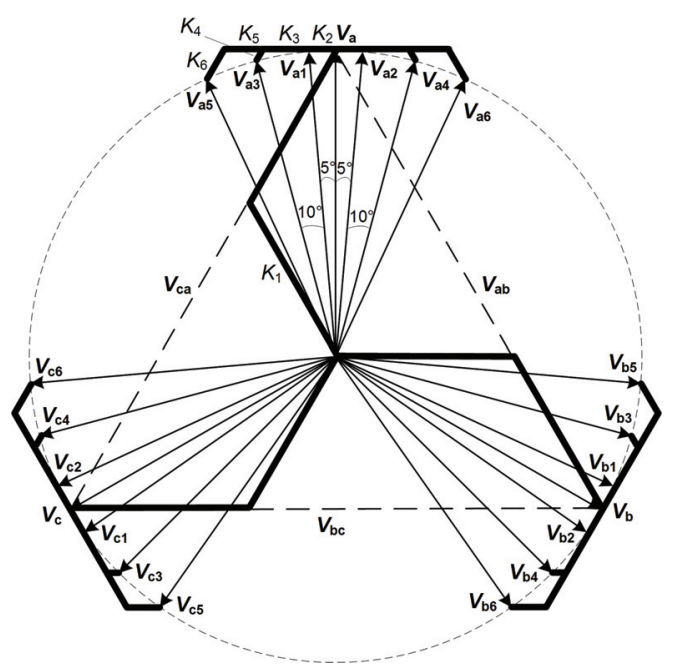

Fig. 3b. Phasor representation of voltages in zigzag autotransformer

\subsection{6-pulse zigzag autotransformer}

The zigzag autotransformer is fed from three-phase input supply voltages $\left(V_{a}, V_{b}, V_{c}\right)$, and it generates the aforementioned six sets of balanced three-phase voltages, i.e. $\left(V_{a 1}, V_{b 1}, V_{c 1}\right)$, 
$\left(V_{a 2}, V_{b 2}, V_{c 2}\right),\left(V_{a 3}, V_{b 3}, V_{c 3}\right),\left(V_{a 4}, V_{b 4}, V_{c 4}\right),\left(V_{a 5}, V_{b 5}, V_{c 5}\right)$, and $\left(V_{a 6}, V_{b 6}, V_{c 6}\right)$ all displaced at an angle of required $10^{\circ}$ for 36-pulse conversion.

To realize the condition of $10^{\circ}$ phase shift, voltages $\left(V_{a 1}, V_{b 1}, V_{c 1}\right)$ and $\left(V_{a 2}, V_{b 2}, V_{c 2}\right)$ are at an angle of $+5^{\circ}$ and $-5^{\circ}$, respectively, with respect to AC mains voltages. Similarly, voltages $\left(V_{a 3}, V_{b 3}, V_{c 3}\right)$ are at $+15^{\circ}$, voltages $\left(V_{a 4}, V_{b 4}, V_{c 4}\right)$ are at $-15^{\circ}$, voltages $\left(V_{a 5}, V_{b 5}, V_{c 5}\right)$ are at $+25^{\circ}$, and voltages $\left(V_{a 6}, V_{b 6}, V_{c 6}\right)$ are at $-25^{\circ}$, with reference to utility voltages. The zigzag connected autotransformer winding configurations for 36-pulse operation is depicted in Figure $3 \mathrm{a}$ and its phasor representation of voltages is shown in Figure $3 \mathrm{~b}$.

It should also be noted that in all converters based on auto-wound transformers, the AC input and DC output are interconnected, implying currents can flow without hindrance from one bridge to others. Therefore, a zero sequence blocking transformer (ZSBT) is required to restrain unfavourable conduction paths and ensure different diode bridges to operate independently. The zigzag connection is known for its ability to block inter-bridge zero sequence currents. Thus, a ZSBT is not needed here.

Suppose three-phase utility voltage applied to the primary windings of autotransformer as:

$$
\begin{gathered}
V_{a}=V_{s} \angle 0^{\circ}, V_{b}=V_{s} \angle-120^{\circ}, V_{c}=V_{s} \angle 120^{\circ}, \\
V_{a b}=\sqrt{3} V_{s} \angle 30^{\circ}, V_{b c}=\sqrt{3} V_{s} \angle-90^{\circ}, V_{c a}=\sqrt{3} V_{s} \angle 150^{\circ} .
\end{gathered}
$$

Where, $V_{s}$ is the root mean square (RMS) value of phase voltage.

The six groups of required voltages for the diode bridges DB1 to DB6 are:

$$
\begin{gathered}
V_{a 1}=V \angle 5^{\circ}, V_{b 1}=V \angle-115^{\circ}, V_{c 1}=V \angle 125^{\circ}, \\
V_{a 2}=V \angle-5^{\circ}, V_{b 2}=V \angle-125^{\circ}, V_{c 2}=V \angle 115^{\circ}, \\
V_{a 3}=V \angle 15^{\circ}, V_{b 3}=V \angle-105^{\circ}, V_{c 3}=V \angle 135^{\circ}, \\
V_{a 4}=V \angle-15^{\circ}, V_{b 4}=V \angle-135^{\circ}, V_{c 4}=V \angle 105^{\circ}, \\
V_{a 5}=V \angle 25^{\circ}, V_{b 5}=V \angle-95^{\circ}, V_{c 5}=V \angle 145^{\circ}, \\
V_{a 6}=V \angle-25^{\circ}, V_{b 6}=V \angle-145^{\circ}, V_{c 6}=V \angle 95^{\circ},
\end{gathered}
$$

Where, $V$ is the RMS value of phase voltage of autotransformer windings.

Furthermore, output voltages of phase ' $a$ ' of the autotransformer, as marked in Figure $3 b$ can be expressed by the following relationships:

$$
\begin{gathered}
V_{s}=V \cos 5^{\circ}, \\
V_{a 1}=K_{1}\left(V_{a b}-V_{c a}\right)-K_{2} V_{b c}, \\
V_{a 2}=K_{1}\left(V_{a b}-V_{c a}\right)+K_{2} V_{b c}, \\
V_{a 3}=K_{1}\left(V_{a b}-V_{c a}\right)-\left(K_{2}+K_{3}\right) V_{b c}+K_{4} V_{c a},
\end{gathered}
$$




$$
\begin{gathered}
V_{a 4}=K_{1}\left(V_{a b}-V_{c a}\right)+\left(K_{2}+K_{3}\right) V_{b c}-K_{4} V_{a b}, \\
V_{a 5}=K_{1}\left(V_{a b}-V_{c a}\right)-\left(K_{2}+K_{3}+K_{5}\right) V_{b c}+K_{6} V_{c a}, \\
V_{a 6}=K_{1}\left(V_{a b}-V_{c a}\right)+\left(K_{2}+K_{3}+K_{5}\right) V_{b c}-K_{6} V_{a b},
\end{gathered}
$$

The values of these constants $K_{1}$ to $K_{6}$ determine the number of turns of secondary windings as a fraction of input phase voltages for the 36-pulse rectifier, which are:

$$
K_{1}=0.577, K_{2}=0.087, K_{3}=0.155, K_{4}=0.035, K_{5}=0.130, K_{6}=0.104 .
$$

Therefore, with this arrangement, the phase-shifting transformer can generate six different groups of voltages all displaced at an angle of $10^{\circ}$ among each other. However, the DC side voltage of the rectifier system is about $1.5 \%$ higher than that of a 6-pulse bridge rectifier, resulting in its limited applications.

\subsection{Modified 36-pulse zigzag transformer for retrofit applications}

In order to make the 36-pulse AC-DC converter appropriate for retrofit applications, the design procedure is modified here. This can be simply realized by varying the tapping positions of the autotransformer while still have the required $10^{\circ}$ phase shift for 36-pulse conversion. Figure 4 diagrammatizes the phasor diagram of various phase voltages to produce different voltage ratios from the proposed transformer. Two winding constructions are given for changing the output voltage of converter, which are called as asymmetric structure and symmetric structure, respectively. The asymmetric structure will be adopted here and its winding constants will be calculated via the following equations:

$$
\begin{gathered}
0.985 V_{s}=V \cos 5^{\circ}, \\
K_{7}+K_{8}=K_{1}, \\
V_{a 1}=K_{1} V_{a b}-K_{7} V_{c a}-K_{9} V_{b c}, \\
V_{a 2}=K_{1} V_{a b}-K_{7} V_{c a}+K_{10} V_{b c}, \\
V_{a 3}=K_{1} V_{a b}-K_{7} V_{c a}-\left(K_{9}+K_{11}\right) V_{b c}+K_{12} V_{c a}, \\
V_{a 4}=K_{1} V_{a b}-K_{7} V_{c a}+\left(K_{10}+K_{11}\right) V_{b c}-K_{12} V_{a b}, \\
V_{a 5}=K_{1} V_{a b}-K_{7} V_{c a}-\left(K_{9}+K_{11}+K_{13}\right) V_{b c}+K_{14} V_{c a}, \\
V_{a 6}=K_{1} V_{a b}-K_{7} V_{c a}+\left(K_{10}+K_{11}+K_{13}\right) V_{b c}-K_{14} V_{a b},
\end{gathered}
$$

The values of these constants can be calculated as:

$$
\begin{gathered}
K_{7}=0.561, K_{8}=0.016, K_{9}=0.078, K_{10}=0.094, K_{11}=0.153, \\
K_{12}=0.035, K_{13}=0.128, K_{14}=0.103 .
\end{gathered}
$$

Winding constants of symmetric structure can also be calculated in a similar way. Hence, the same DC link voltage as that of a 6-pulse diode bridge rectifier is achieved by just changing the transformer winding taping positions. 


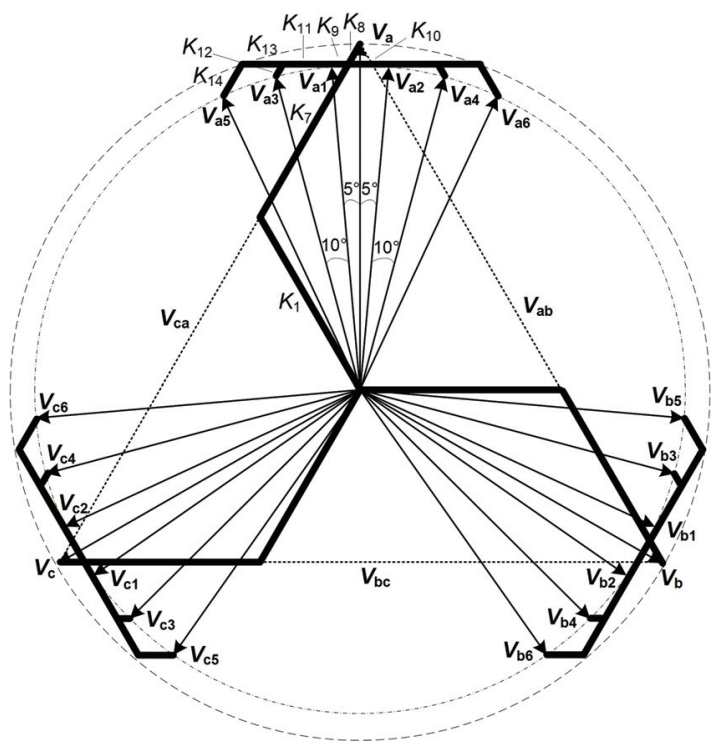

Fig. 4a. Phasor diagram of voltages in modified zigzag autotransformer (asymmetric structure)

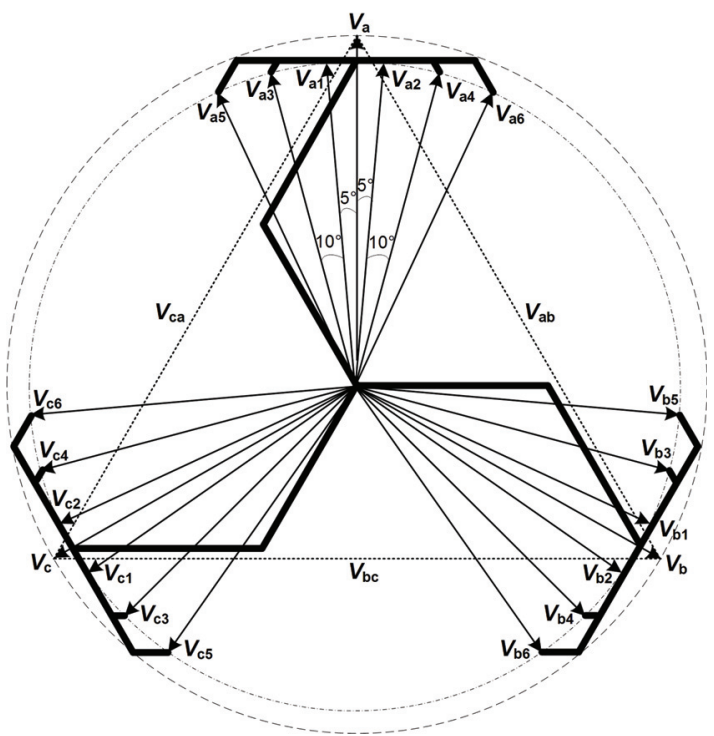

Fig. 4b. Phasor diagram of voltages in modified zigzag autotransformer (symmetric structure)

\subsection{Interphase reactor}

The output voltages of the autotransformer are given to six diode bridges. A small rating interphase reactor (IPR) is needed to absorb the instantaneous differences in the output voltages of the six diode bridges, all displaced by an angle of $10^{\circ}$ among each other. Winding configuration of the IPR is shown in Figure 5. Interphase reactor can ensure the independent operation of different rectifier bridges and $120^{\circ}$ conduction of each diode per cycle. The DC 
link voltage at any instant is the average value of output voltages of the six bridge rectifiers and it fluctuates with 36-pulse ripples periodically.

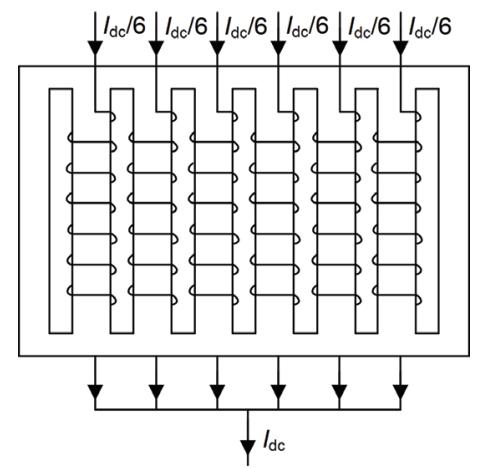

Fig. 5. Winding configuration of interphase reactor

The IPR consists of a central core with six legs and all of them are excited in the same direction, preventing IPR from entering saturation. Air gaps in the core of the magnetics to change the saturation point can be used when saturation is inevitable.

\subsection{Calculation of the autotransformer and IPR $\mathrm{kVA}$ rating}

The magnetic rating of the proposed zigzag transformer and the interphase reactor are calculated in this section. The kVA rating of the autotransformer is calculated by [6]:

$$
\mathrm{kVA}=0.5 \times \frac{\sum V_{r m s} \times I_{r m s}}{1000} .
$$

Where $V_{r m s}$ is the voltage across each transformer winding and $I_{r m s}$ is the current through each transformer winding.

Assume that output load is a large inductance and commutation overlap is neglected. Let the RMS values of the current through the windings $K_{1}$ and $K_{7}$ to $K_{14}$ as shown in Figure 4a are $I_{K 1}$ and $I_{K 7}$ to $I_{K 14}$, respectively. Similarly, the RMS values of the voltage across the windings $K_{1}$ and $K_{7}$ to $K_{14}$ are $V_{K 1}$ and $V_{K 7}$ to $V_{K 14}$, respectively. The RMS values of each of the winding currents and voltages can be obtained as shown in Table 1.

The magnetic rating of the proposed 36-pulse zigzag auto-connected transformer in terms of output DC voltage and current is calculated as:

$$
\begin{aligned}
& \mathrm{VA}_{\text {transformer }}=0.5 \times 3 \times\left[\left(I_{K 1} V_{K 1}+I_{K 7} V_{K 7}+I_{K 8} V_{K 8}+I_{K 9} V_{K 9}+I_{K 10} V_{K 10}\right.\right. \\
& \left.+2\left(I_{K 11} V_{K 11}+I_{K 12} V_{K 12}+I_{K 13} V_{K 13}+I_{K 14} V_{K 14}\right)\right] \\
& =0.5 \times 3 \times\left[0.049 I_{\mathrm{dc}} \times 0.253 V_{\mathrm{dc}}+0.049 I_{\mathrm{dc}} \times 0.246 V_{\mathrm{dc}}\right. \\
& +0.775 I_{\mathrm{dc}} \times 0.007 V_{\mathrm{dc}}+0.395 I_{\mathrm{dc}} \times 0.034 V_{\mathrm{dc}}+0.395 I_{\mathrm{dc}} \times 0.041 V_{\mathrm{dc}} \\
& +2 \times\left(0.268 I_{\mathrm{dc}} \times 0.067 V_{\mathrm{dc}}+0.136 I_{\mathrm{dc}} \times 0.015 V_{\mathrm{dc}}+0.137 I_{\mathrm{dc}} \times 0.056 V_{\mathrm{dc}}\right. \\
& \left.\left.+0.137 I_{\mathrm{dc}} \times 0.045 V_{\mathrm{dc}}\right)\right]=0.191 V_{\mathrm{dc}} I_{\mathrm{dc}}=0.191 P_{\mathrm{dc}},
\end{aligned}
$$


Where $P_{\mathrm{dc}}=V_{\mathrm{dc}} I_{\mathrm{dc}}$ is the DC side output load.

Similarly, the magnetic rating of the two interphase reactors is given by:

$$
\mathrm{VA}_{\mathrm{IPR}}=0.5 \times 2 \times\left(6 \times 0.168 I_{\mathrm{dc}} \times 0.039 V_{\mathrm{dc}}\right)=0.039 P_{\mathrm{dc}} .
$$

Therefore, the magnetic rating of the 36-pulse zigzag autotransformer and IPR is approximately $19.1 \%$ and $3.9 \%$ of the DC side output load, respectively. The total magnetic rating of the rectifier scheme is only $23 \%$ of the load. Thus, the low kVA rating magnetics can reduce the cost, space, and weight of the whole system.

Table 1. Winding currents and voltages of the 36-pulse zigzag transformer

\begin{tabular}{c|c|c|c|c|c|c|c|c}
\hline $\boldsymbol{I}_{\boldsymbol{K} \mathbf{1}}$ & $\boldsymbol{I}_{\boldsymbol{K} \mathbf{7}}$ & $\boldsymbol{I}_{\boldsymbol{K} \mathbf{8}}$ & $\boldsymbol{I}_{\boldsymbol{K} \mathbf{9}}$ & $\boldsymbol{I}_{\boldsymbol{K} \mathbf{1 0}}$ & $\boldsymbol{I}_{\boldsymbol{K} \mathbf{1 1}}$ & $\boldsymbol{I}_{\boldsymbol{K} \mathbf{2}}$ & $\boldsymbol{I}_{\boldsymbol{K} \mathbf{3}}$ & $\boldsymbol{I}_{\boldsymbol{K} \mathbf{1 4}}$ \\
\hline $0.049 I_{\mathrm{dc}}$ & $0.049 I_{\mathrm{dc}}$ & $0.775 I_{\mathrm{dc}}$ & $0.395 I_{\mathrm{dc}}$ & $0.395 I_{\mathrm{dc}}$ & $0.268 I_{\mathrm{dc}}$ & $0.136 I_{\mathrm{dc}}$ & $0.137 I_{\mathrm{dc}}$ & $0.137 I_{\mathrm{dc}}$ \\
\hline$V_{\mathrm{K} 1}$ & $V_{\mathrm{K} 7}$ & $V_{\mathrm{K} 8}$ & $V_{\mathrm{K} 9}$ & $V_{\mathrm{K} 10}$ & $V_{\mathrm{K} 11}$ & $V_{\mathrm{K} 12}$ & $V_{\mathrm{K} 13}$ & $V_{\mathrm{K} 14}$ \\
\hline $0.253 V_{\mathrm{dc}}$ & $0.246 V_{\mathrm{dc}}$ & $0.007 V_{\mathrm{dc}}$ & $0.034 V_{\mathrm{dc}}$ & $0.041 V_{\mathrm{dc}}$ & $0.067 V_{\mathrm{dc}}$ & $0.015 V_{\mathrm{dc}}$ & $0.056 V_{\mathrm{dc}}$ & $0.045 V_{\mathrm{dc}}$ \\
\hline
\end{tabular}

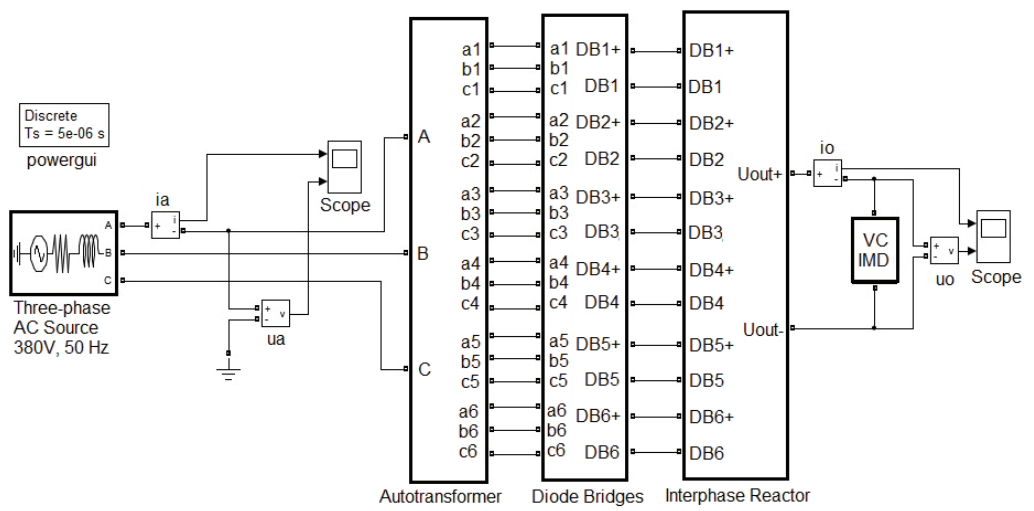

Fig. 6a. MATLAB model of the proposed 36-pulse rectifier system

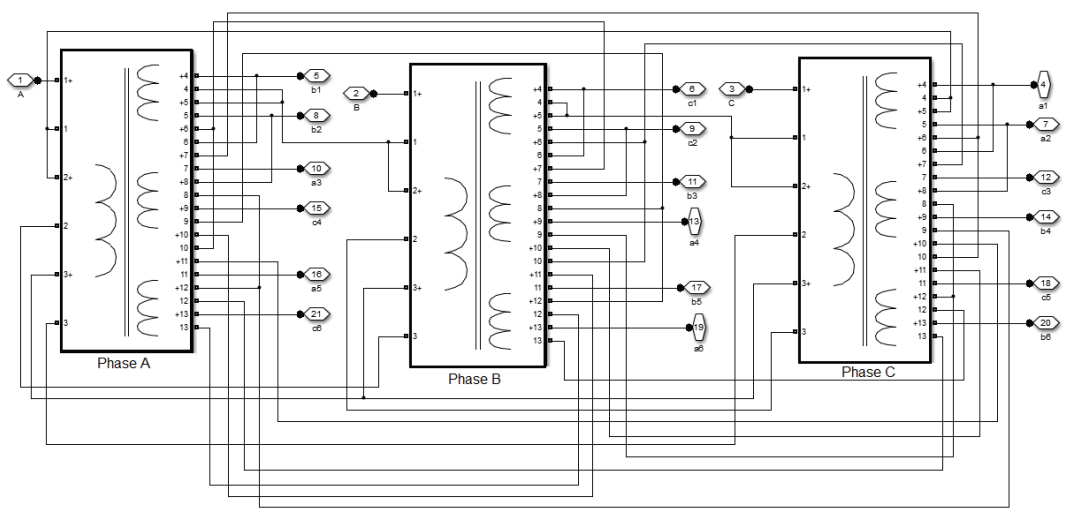

Fig. 6b. MATLAB model of 36-pulse zigzag auto-connected transformer for retrofit applications 


\section{Simulations based on MATLAB}

The proposed 36-pulse AC-DC converter is modeled and simulated in MATLAB/Simulink along with SimPowerSystems toolbox. A three-phase $380 \mathrm{~V}, 50 \mathrm{~Hz}$ AC voltage source is adopted as the power supply for the rectifier. Output of the rectifier is connected to IGBT based inverter, and the inverter drives a $20 \mathrm{hp}(15 \mathrm{~kW})$ VCIMD load. Figure 6 shows simulation model of the proposed 36-pulse rectifier scheme and phase-shifting autotransformer. The proposed 36-pulse zigzag autotransformer is constructed by three single-phase multi-winding transformers. Each of the three transformers has thirteen windings. In all simulations, the source impedance is kept at a practical value of 0.03 (p.u.), and the leakage reactance of the autotransformer is set to be 0.02 (p.u.). The results obtained from simulations are depicted in Figures 7-11 and Tables 2-5.

Table 2. Comparison of power quality parameters of four different topologies

\begin{tabular}{c|c|c|c|c|c|c|c|c|c|c|c|c|c|c}
\hline \multirow{2}{*}{$\begin{array}{c}\text { Topo- } \\
\text { logy }\end{array}$} & \multicolumn{2}{|c|}{$\mathbf{T H D}_{\boldsymbol{v}}(\mathbf{\%})$} & \multicolumn{2}{c|}{$\mathbf{T H D}_{\boldsymbol{i}}(\mathbf{\%})$} & \multicolumn{2}{c|}{$\boldsymbol{I}_{\mathbf{s}}(\mathbf{A})$} & \multicolumn{2}{c|}{ DF } & \multicolumn{2}{|c|}{ DPF } & \multicolumn{2}{|c|}{ PF } & \multicolumn{2}{c}{$\boldsymbol{V}_{\mathbf{d c}}(\mathbf{V})$} \\
\hline & FL & LL & FL & LL & FL & LL & FL & LL & FL & LL & FL & LL & FL & LL \\
\hline A & 5.01 & 1.88 & 26.4 & 48.4 & 24.5 & 4.98 & .966 & .943 & .957 & .932 & .924 & .879 & 503 & 511 \\
\hline B & 3.19 & 1.12 & 5.04 & 5.79 & 23.6 & 4.80 & .999 & .998 & .998 & .996 & .998 & .995 & 511 & 516 \\
\hline C & 2.66 & 0.93 & 3.03 & 3.58 & 23.5 & 4.79 & .999 & .998 & .998 & .997 & .998 & .996 & 509 & 514 \\
\hline D & 2.68 & 0.93 & 3.03 & 3.60 & 23.5 & 4.79 & .999 & .998 & .998 & .997 & .998 & .996 & 503 & 510 \\
\hline
\end{tabular}

Notes: A: 6-pulse rectifier; B: 24-pulse rectifier; C: the proposed 36-pulse rectifier; D: the proposed 36pulse rectifier for retrofit applications; FL: full load; LL: light load; $\mathrm{THD}_{v}$ : THD of supply voltage at PCC; THD $_{i}$ : THD of supply current; $I_{\mathrm{s}}$ : RMS value of input supply current; DF: distortion factor; DPF: displacement factor; PF: power factor; $V_{\mathrm{dc}}$ : average $\mathrm{DC}$ side output voltage.

Table 3. Power quality indices of the 36-pulse rectifier for retrofit applications under varying loads

\begin{tabular}{c|c|c|c|c|c|c|c|c}
\hline Load (\%) & THD $_{\boldsymbol{v}}(\mathbf{\%})$ & $\mathbf{T H D}_{\boldsymbol{i}}(\mathbf{\%})$ & $\boldsymbol{I}_{\mathbf{s}} \mathbf{( A )}$ & $\mathbf{D F}$ & $\mathbf{D P F}$ & $\mathbf{P F}$ & $\boldsymbol{V}_{\text {dc }}(\mathbf{V})$ & $\mathbf{R F}(\mathbf{\%})$ \\
\hline 20 & 0.93 & 3.60 & 4.79 & .998 & .997 & .996 & 509.7 & 0.21 \\
\hline 40 & 1.47 & 3.49 & 9.40 & .998 & .997 & .996 & 507.6 & 0.24 \\
\hline 60 & 1.89 & 3.35 & 13.8 & .999 & .997 & .997 & 505.5 & 0.26 \\
\hline 80 & 2.32 & 3.18 & 18.6 & .999 & .998 & .998 & 504.3 & 0.30 \\
\hline 100 & 2.68 & 3.03 & 23.5 & .999 & .998 & .998 & 503.1 & 0.34 \\
\hline
\end{tabular}

Table 4. Comparison of power quality indices of the 36-pulse rectifier under capacitive, inductive and resistive load

\begin{tabular}{c|c|c|c|c|c|c|c|c}
\hline Load type & $\mathbf{T H D}_{\boldsymbol{v}}(\mathbf{\%})$ & $\mathbf{T H D}_{\boldsymbol{i}}(\mathbf{\%})$ & $\boldsymbol{I}_{\mathbf{s}} \mathbf{( A )}$ & $\mathbf{D F}$ & $\mathbf{D P F}$ & $\mathbf{P F}$ & $\boldsymbol{V}_{\text {dc }}(\mathbf{V})$ & $\mathbf{R F}(\mathbf{\%})$ \\
\hline capacitive & 0.08 & 6.38 & 1.89 & .998 & .999 & .997 & 527 & 0.09 \\
\hline inductive & 2.96 & 2.85 & 25.9 & .999 & .999 & .998 & 502 & 0.40 \\
\hline resistive & 2.96 & 2.86 & 25.9 & .999 & .999 & .998 & 502 & 0.19 \\
\hline
\end{tabular}


Table 5. Comparison of magnetic rating for various converters based on autotransformers

\begin{tabular}{c|c|c|c}
\hline Transformer type & $\begin{array}{c}\text { Main transformer rating } \\
\text { (\% of load) }\end{array}$ & $\begin{array}{c}\text { Interphase reactor rating } \\
\text { (\% of load) }\end{array}$ & $\begin{array}{c}\text { Total magnetic rating } \\
\text { (\% of load) }\end{array}$ \\
\hline $\begin{array}{c}\text { isolated } \\
\Delta / \text { Y/ } 12 \text {-pulse }\end{array}$ & 103 & 6.6 & 109.6 \\
\hline $\begin{array}{c}\text { T-connected } \\
\text { 24-pulse }\end{array}$ & 33.5 & 6.4 & 39.9 \\
\hline $\begin{array}{c}\text { fork-connected } \\
\text { 18-pulse }\end{array}$ & 32.7 & 7.0 & 39.7 \\
\hline $\begin{array}{c}\text { star-connected } \\
\text { 24-pulse }\end{array}$ & 84.8 & 6.2 & 91.0 \\
\hline polygon 20-pulse & 41.0 & 4.5 & 45.5 \\
\hline $\begin{array}{c}\text { T-connected } \\
\text { 36-pulse }\end{array}$ & 61.5 & 0.4 & 61.9 \\
\hline $\begin{array}{c}\text { proposed zigzag } \\
\text { 36-pulse }\end{array}$ & 18.4 & 3.4 & 21.8 \\
\hline
\end{tabular}

\section{Results and discussion}

To investigate the improvement in performance of the proposed rectifier system based on 36-pulse zigzag connected autotransformer, a traditional 6-pulse diode bridge rectifier and a zigzag autotransformer based 24-pulse rectifier [20] have also been modelled and simulated.

For simplicity, the 6-pulse rectifier, 24-pulse rectifier, 36-pulse rectifier and 36-pulse rectifier for retrofit applications are referred to as topology ' $\mathrm{A}$ ', topology ' $\mathrm{B}$ ', topology ' $\mathrm{C}$ ' and topology ' $\mathrm{D}$ ', respectively.

\subsection{Performance of 6-pulse rectifier}

The 6-pulse AC-DC converter's THD of supply current at full load is $26.4 \%$, which deteriorates to $48.4 \%$ at light load ( $20 \%$ of full load). The PF is 0.924 under full load and 0.879 under light load, respectively. The results are given in Table 2, which shows that 6-pulse rectifier injects large harmonics into the power grid and thus cannot comply with IEEE standard 519-1992 [4].

\subsection{Performance of 24-pulse rectifier}

To improve the power quality indices, a 24-pulse AC-DC converter based on zigzag autotransformer has been designed and simulated. The THD of AC mains current at full load is $5.04 \%$ and at light load which is $5.79 \%$. The PF is 0.998 and 0.995 , respectively, in these conditions. However, DC link voltage is somewhat higher than that of a 6-pulse rectifier, thus making it unsuitable for retrofit applications. It's rather clear that the THD of input line current in topology ' $\mathrm{B}$ ' is within acceptable limits for systems with short circuit ratio (SCR) greater than twenty [4]. 


\subsection{Performance of the proposed 36-pulse rectifier scheme}

In topology ' $\mathrm{C}$ ', the THD of $\mathrm{AC}$ mains current under full load and light load as given in Table 2 is $3.03 \%$ and $3.58 \%$, and the PF under these conditions is 0.998 and 0.996 , respectively. But the DC side voltage $V_{\mathrm{dc}}$ is higher compared with that of a 6-pulse rectifier. The results are shown in Table 2.

The design of the proposed zigzag autotransformer is modified for applications where a 6pulse diode rectifier bridge is being used. The arrangement of the modified transformer is very similar to the proposed 36-pulse zigzag autotransformer except for the small differences in number of turns in the winding tapings.

In the proposed 36-pulse rectifier scheme for retrofit applications, the THD of input line current under full load can be observed to be 3.03\% as shown in Figure 7, whereas the PF is 0.998 as given in Table 3. Under light load condition, the THD of utility line current is $3.60 \%$ and the PF obtained is 0.996 , as depicted in Figure 8 and Table 3, respectively. The output voltage of topology ' $\mathrm{D}$ ' is very similar to that of an existing 6-pulse rectifier.
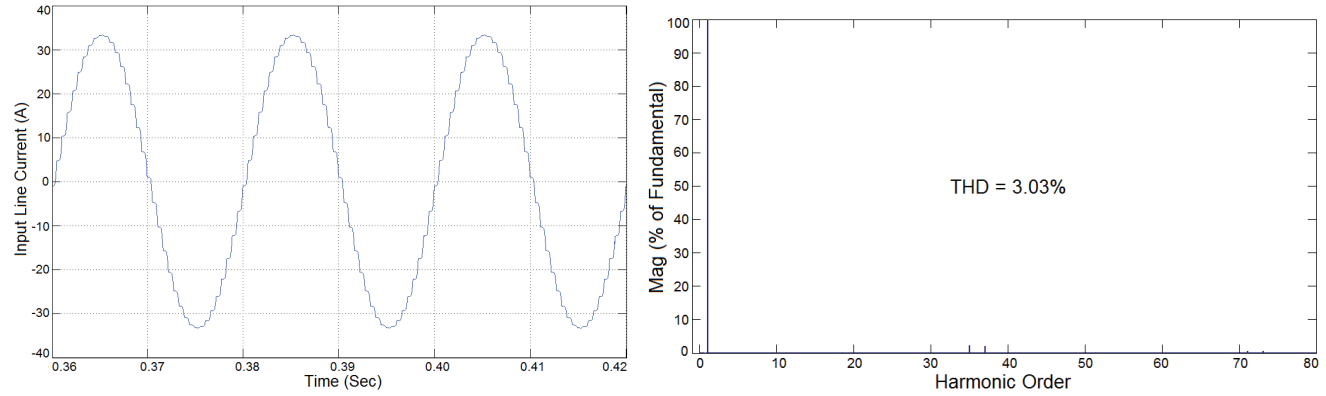

Fig. 7. Input line current waveform and its spectrum at full load of the proposed 36-pulse rectifier for retrofit applications
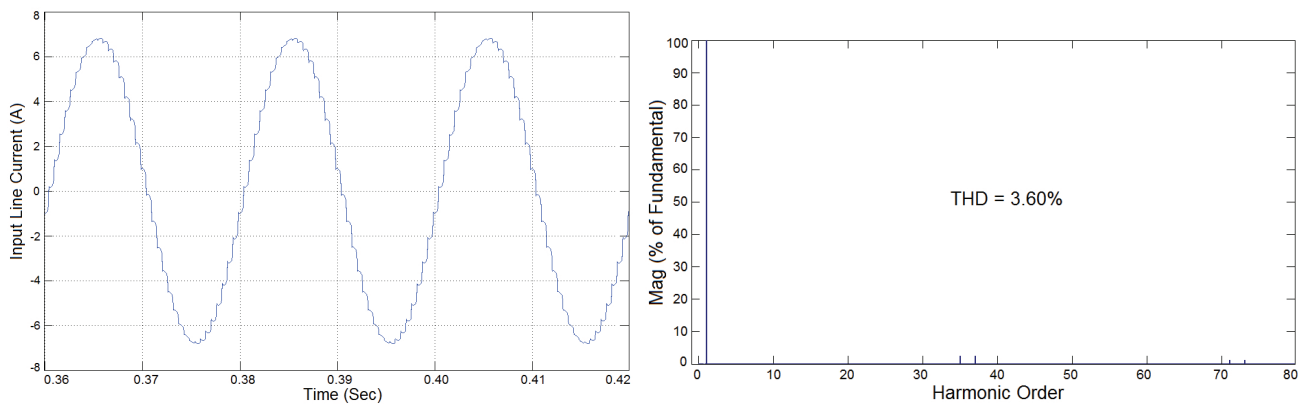

Fig. 8. Input line current waveform and its spectrum at light load of the proposed 36-pulse rectifier for retrofit applications

Figure 9 illustrates input phase voltage waveforms at full load and light load, respectively. The utility voltage waveforms are very near sinusoidal, so the system injects little harmonics at the PCC. DC link current and voltage waveforms at full load and light load conditions are also depicted in Figure 10. The current ripple is less than $0.01 \mathrm{~A}$, and voltage ripple is less 
than $2 \mathrm{~V}$, reducing the size and cost of the L-C filter. Besides, output current and voltage have thirty-six pulses per cycle. Hence, the proposed converter can mitigate both AC side and DC side harmonic components. Figure 11 shows variation of THD of utility current and PF with load perturbation on the 6-, 24-, and 36-pulse rectifiers, respectively. It is obvious that 36-pulse rectifier bring about considerable improvement in THD of supply current and power factor.
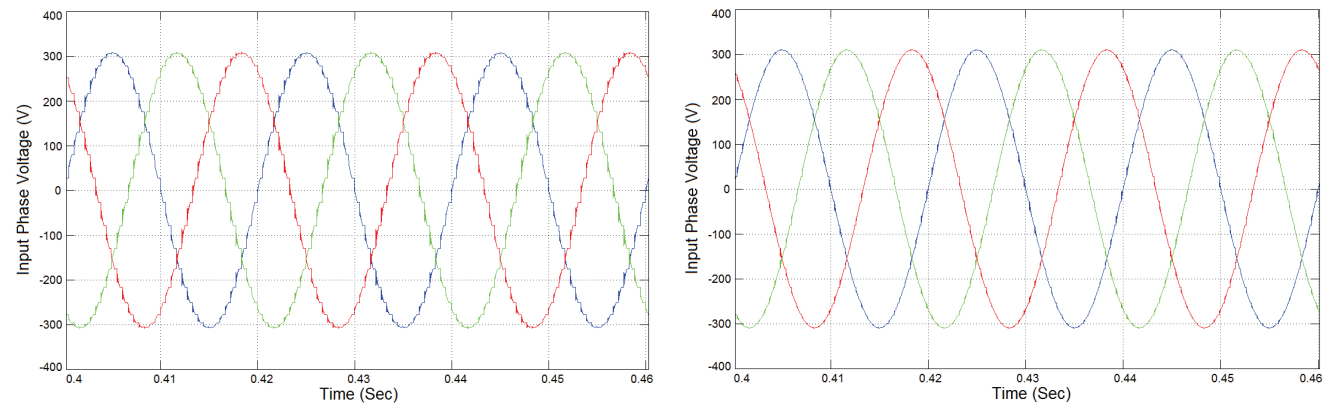

Fig. 9. Input phase voltage waveforms at full load and light load of the proposed 36-pulse rectifier for retrofit applications
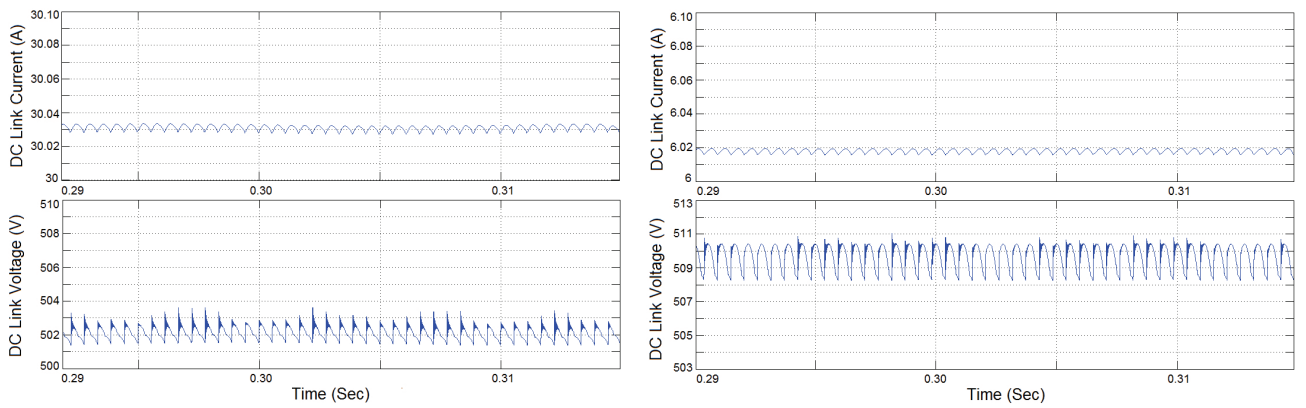

Fig. 10. DC link current and voltage waveforms at full load and light load of the proposed 36-pulse rectifier for retrofit applications
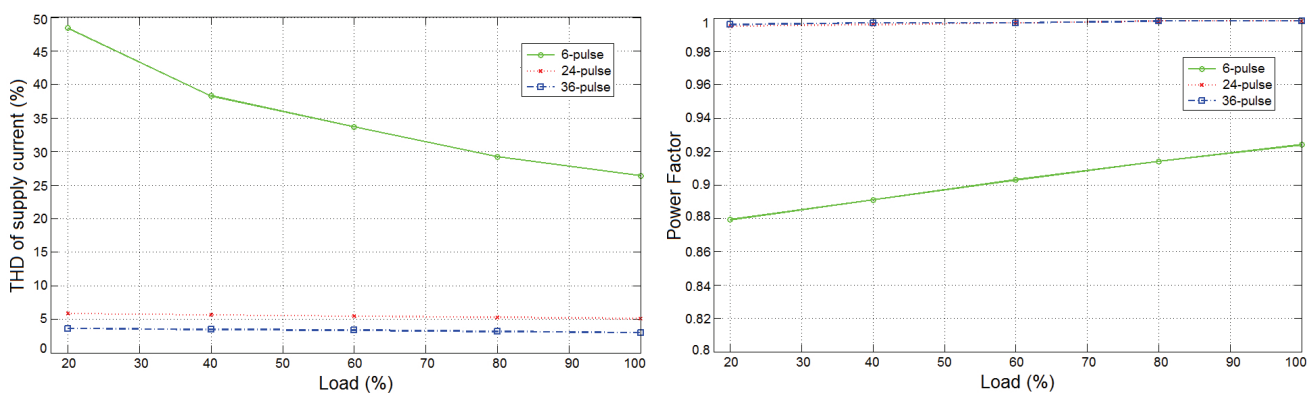

Fig. 11. Variation of THD of supply current and PF with load for 6-, 24-, and 36-pulse converter

To study the effect of load variation on different power quality parameters, the load is varied on the VCIMD. Table 3 shows that the THD of AC mains current is always below 4\%, 
which is within IEEE Standard 519-1992 limits for systems with SCR less than twenty [4]. The PF is also improved to near unity under varying loads.

In a word, the greatly improved performance of the proposed 36-pulse rectifier system makes power quality indices such as $\mathrm{THD}_{i}, \mathrm{THD}_{v}, \mathrm{DF}, \mathrm{DPF}$, and PF satisfactory for various load conditions.

Simulations on a capacitive load $(C=4700 \mu \mathrm{F}, R=15 \Omega)$, an inductive load ( $L=40 \mathrm{mH}$, $R=15 \Omega)$, and a resistive load $(R=15 \Omega)$ are discussed here to study the effect of load character on various power quality indices, which is tabulated in Table 4 . It can be obtained from Table 4 that when output load is capacitive, $\mathrm{THD}_{v}$ is only $0.08 \%$ while $\mathrm{THD}_{i}$ is $6.38 \%$, meaning that input line voltage is almost sinusoidal while input line current is still distorted. Moreover, output voltage $V_{\mathrm{dc}}$ and power factor are deteriorated while ripple factor is improved compared with when load is inductive or resistive. AC mains current decreases gradually to only 1.89A RMS, indicating that power backflow will happen if load is capacitive. So, the proposed AC-DC converter can only realize unidirectional power flow. If bidirectional power flow is required, all the diode bridges should be replaced by thyristor based bridges. Performance of the converter is almost the same when load is either inductive or resistive, except for tiny difference in ripple factor.

It can also be obtained from simulations that the proposed 36-pulse harmonic mitigator for retrofit applications needs a zigzag auto-wound transformer of $2.753 \mathrm{kVA}$, two interphase reactors of $0.516 \mathrm{kVA}$, totaling all the required magnetics of $3.269 \mathrm{kVA}$, that is to say, only $21.8 \%$ of the load power rating. The difference in the magnetic ratings of calculation value $(23 \%)$ and simulation value $(21.8 \%)$ can be due to the effect of the leakage reactance of the zigzag autotransformer and relatively small load inductance. When calculating the magnetic rating theoretically, the autotransformer is considered to have negligible leakage reactance. However, in simulation, the autotransformer is considered to have a finite value of leakage reactance, leading to commutation overlap. In comparison with the total magnetics ratings of conventional $\Delta / Y / \Delta$ 12-pulse isolated transformer (109.6\%) [6], T-connected 24-pulse autotransformer (39.9\%) [7], fork-connected 18-pulse autotransformer (39.7\%) [9], star-connected 24-pulse autotransformer (91.0\%) [13], asymmetrical polygon 20-pulse autotransformer (45.5\%) [17], and T-connected 36-pulse autotransformer (61.9\%) [22] based AC-DC converters, the total ratings of magnetics of the proposed 36-pulse rectifier scheme is much less. The detailed comparison results are tabulated in Table 5.

Although increasing the pulse number can bring dramatic improvement in different power quality indices, it will also make the autotransformer configuration become cumbersome and more diode bridge rectifiers will be required, leading to increased components and cost in the overall AC-DC converter system.

\section{Conclusions}

In this paper, a zigzag connected autotransformer based 36-pulse rectifier has been designed, constructed and simulated for a VCIMD load. The proposed scheme is capable of eli- 
minating up to $33^{\text {rd }}$ harmonics in the AC mains current. The proposed rectifier has the flexibility to vary the dc link voltage, simply by changing the ratio of number of turns of the transformer, which makes it suitable for retrofit applications. The low equivalent $\mathrm{kVA}$ rating of the proposed zigzag auto-connected transformer has resulted in a system of lower volume, weight, losses and cost compared with other types of autotransformer configuration based AC-DC converters. The simulation results have shown that the THD of input current remains below $4.0 \%$ and the power factor is always above 0.995 in the wide operating range of the loads. The improvement in power quality indices and reduction in magnetics is considerable in the proposed 36-pulse rectifier.

\section{Acknowledgement}

The authors thank the anonymous referees for their helpful and constructive comments and suggestions. The project presented in this article is supported by the Science and Technology Plan Project of Gansu Province (145RJZA098).

\section{References}

[1] Vas P., Sensorless Vector and Direct Torque Control. Oxford University Press (1998).

[2] Nguyen-Thac K., Orlowska-Kowalska T., Tarchala G., Comparative analysis of the chosen fieldweakening methods for the Direct Rotor Flux Oriented Control drive system. Archives of Electrical Engineering 61(4): 443-454 (2012).

[3] Singh B., Gairola S., Singh B.N. et al., Multipulse AC-DC converters for improving power quality: a review. IEEE Trans. on Power Electronics 23(1): 260-281(2008).

[4] Institute of Electrical and Electronic Engineers (IEEE), IEEE Standard 519-1992, IEEE Guide for Harmonic Control and Reactive Compensation of Static Power Converters. IEEE Inc. (1992).

[5] International Electrotechnical Commission (IEC), International Electrotechnical Commission Standard 61000-3-2: 2014, Limits for Harmonic Current Emissions. IEC (2014).

[6] Paice D.A., Power Electronic Converter Harmonics: Multipulse Methods for Clean Power. IEEE Press (1996).

[7] Singh B., Bhuvaneswari G., Garg V., T-Connected Autotransformer-Based 24-Pulse AC-DC Converter for Variable Frequency Induction Motor Drives. IEEE Trans. on Energy Conversion 21(3): 663-672 (2006).

[8] Singh B., Bhuvaneswari G., Garg V., Harmonic Mitigation Using 12-Pulse AC-DC Converter in Vector-Controlled Induction Motor Drives. IEEE Trans. on Power Delivery 21(3): 1483-1492 (2006).

[9] Singh B., Bhuvaneswari G., Garg V., Harmonic Mitigation in AC-DC Converters for Vector Controlled Induction Motor Drives. IEEE Trans. on Energy Conversion 22(3): 637-646 (2007).

[10] Singh B., Bhuvaneswari G., Garg V., An Improved Power-Quality 30-Pulse AC-DC for Varying Loads. IEEE Trans. on Power Delivery 22(2): 1179-1187 (2007).

[11] Singh B., Garg V., Bhuvaneswari G., A Novel T-Connected Autotransformer-Based 18-Pulse $A C-D C$ Converter for Harmonic Mitigation in Adjustable-Speed Induction-Motor Drives. IEEE Trans. on Industrial Electronics 54(5): 2500-2511 (2007).

[12] Singh B., Gairola S., A 28-pulse ac-dc converter for line current harmonic reduction. IET Power Electronics 1(2): 287-295 (2008).

[13] Singh B., Gairola S., Star-Connected Autotransformer-Based Full-Wave AC-DC Converters. International Journal of Emerging Electric Power Systems 9(5): 1-16 (2008).

[14] Garg V., Singh B., Bhuvaneswari G., 24-pulse ac-dc converter for harmonic mitigation. IET Power Electronics 3(6): 364-374 (2009). 
[15] Singh B., Bhuvaneswari G., Kalpana R., Autoconnected transformer-based 18-pulse ac-dc converter for power quality improvement in switched mode power supplies. IET Power Electronics 3(4): 524-541 (2010).

[16] Kalpana R., Bhuvaneswari G., Singh B., Singh S., Harmonic mitigator based on 12-pulse ac-dc converter for switched mode power supply. IET Power Electronics 3(6): 947-964 (2010).

[17] Kalpana R., Bhuvaneswari G., Singh B. et al., Autoconnected-Transformer-Based 20-Pulse AC-DC Converter for Telecommunication Power Supply. IEEE Trans. on Industrial Electronics 60(10): 4178-4190 (2013).

[18] Oliveira P.S., Seixas F.J.M., Fernandes R.C., Optimization of Multipulse Converters with Delta and Y-differential Connections. Power Electronics Conference 2009 (COBEP’09), Bonito, pp. 901-907 (2009).

[19] Fernandes R.C., Oliveira P.S., Seixas F.J.M., A Family of Autoconnected Transformers for 12- and 18-pulse Converters - Generalization for Delta and Wye Topologies. IEEE Trans. on Power Electronics 26(7): 2065-2078 (2011).

[20] Chen X., Qiu H., Zigzag Connected Autotransformer-Based 24-pulse AC-DC Converter. International Journal of Emerging Electric Power Systems 16(1): 23-32 (2015).

[21] Qiu H., Chen X., Lu M., A delta-type autotransformer based 36-pulse AC-DC converter. Australian Journal of Electrical \& Electronics Engineering 12(1): 13-21 (2015).

[22] Abdollahi R., T-connected Autotransformer Based 36-Pulse AC-DC Converter for Power Quality Improvement, Electrical Review (Przeglad Elektrotechniczny) 88(2): 321-327 (2012).

[23] Abdollahi R., Study of delta/polygon-connected transformer-based 36-pulse ac-dc converter for power quality improvement. Archives of Electrical Engineering 61(2): 277-292 (2012).

[24] Abdollahi R., Design and Construction of a Polygon-Connected Autotransformer-Based 36-Pulse $A C-D C$ Converter for Power Quality Improvement in Retrofit Applications. Bulletin of the Polish Academy of Sciences 63(2): 353-362 (2015).

[25] Abdollahi R., Harmonic Mitigation using 36-Pulse AC-DC Converter for Direct Torque Controlled Induction Motor Drives. Journal of Applied Research and Technology 13(1): 135-144 (2015).

[26] Nakhaee S., Jalilian A., Simulation of 24-Pulse Autotransformer based AC-DC Converter Employing Pulse Multiplication with Direct Torque Controlled Induction Motor Drive Load, 2nd Power Electronics. Drive Systems and Technologies Conference (PEDSTC), Tehran, pp. 593-598 (2011).

[27] Abdollahi R., Pulse Doubling in Zigzag-Connected Autotransformer-Based 12-Pulse AC-DC Converter for Power Quality Improvement. Journal of Electrical Engineering 63(6): 357-364 (2012).

[28] Chen X., Qiu H., Hao C., Li M., Pulse Doubling in AC-DC Converters Based on Zigzag Auto-Connected Transformer for Harmonic Mitigation. International Journal of Electrical Engineering 22(1): 9-19 (2015).

[29] Singh B., Gairola S., Chandra A., Al-Haddad K., Zigzag Connected Autotransformer Based Controlled $A C-D C$ Converter for Pulse Multiplication. IEEE International Symposium on Industrial Electronics (ISIE), Vigo, pp. 889-894 (2007). 